This is the accepted manuscript of a paper published in Ocean and Coastal Management. The final version may be accessed at http://dx.doi.org/10.1016/j.ocecoaman.2018.03.004.

This paper is available under a CC-BY-NC-ND license. 


\title{
Marine functional zoning: A practical approach for integrated coastal management (ICM) in Xiamen
}

\author{
Qinhua Fang ${ }^{\mathrm{a},}$, Deqiang Ma ${ }^{\mathrm{b}}$, Liyu Zhang ${ }^{\mathrm{c}}$, Shouqin Zhu ${ }^{\mathrm{b}}$ \\ ${ }^{a}$ Fujian Provincial Key Laboratory for Coastal Ecology and Environmental Studies, Coastal and Ocean Management Institute, Xiamen University, China \\ ${ }^{\mathrm{b}}$ Coastal and Ocean Management Institute, Xiamen University, China \\ ${ }^{c}$ Xiamen Oceans and Fisheries Institute, Xiamen, 361000, China
}

\section{A R T I CLE IN F O}

\begin{abstract}
A B S T R A C T
Xiamen has marked its integrated coastal management (ICM) practice as PEMSEA's demonstration site since the 1990s. However, the role of Marine Functional Zoning (MFZ) in ICM has not been fully explored yet even though planning has been highlighted in some literature on Xiamen ICM mode. To showcase the contribution of MFZ as a practical approach to Xiamen ICM, the five dimensions of integration in ICM is applied as an analysis framework. Firstly, through compiling of the historical data and documents of the sea uses and marine environments, and socioeconomic status as well, the key drivers of initiating MFZ in the 1990s is summarized as increasing but incompatible and even conflicting sea uses, degrading marine environments due to negative effects of intensified human activities, and the lack of coordinating mechanism which has worsened the use-use and use-environment conflicts. Secondly, the technical guidelines and adaptive evolvement of Xiamen MFZ is introduced, and the achievements of Xiamen MFZ is explored. Based on the above analysis, the relationships of MFZ and ICM is looked into the dimensions of legislation, coordinating mechanism, scientific and technical support, integrated law enforcement and public participation; and how MFZ contributes to ICM in integration of dimensions of intergovernmental, inter-sectoral, land and sea, science and management, and multiple disciplinary is analyzed in-depth. It is concluded that MFZ has been a working approach in Xiamen to realize ICM from a conceptual call to a good practice on the ground, even challenges remain.
\end{abstract}

\section{Introduction}

Marine spatial planning (MSP) is a cross-sector and area-based management tool, aiming at promoting sustainable exploitation and utilization of marine and ocean-related resources as well as marine environmental protection (Douvere, 2008; Douvere and Ehler, 2009). MSP started as a conservation tool in Australia (Day, 2002; Kenchington and Day, 2011), then it was developed to an ecosystem-based management ocean zoning tool to guide and harmonize ocean-related activities in spatial and temporal dimensions (Ehler and Douvere, 2006; Gilliland and Laffoley, 2008). Over past three decades' development, MSP has been widely accepted as an effective measure to address sea use conflicts and conflicts between ocean development and conservation by the international community (Santos et al., 2016). Increasing States and local governments including Australia, USA, Canada, European Union countries et al. have implemented MSP in marine areas under their own jurisdiction (Agardy et al., 2011; Collie et al., 2013; Olsen et al., 2014; Vince, 2014).

In China, marine functional zoning (MFZ) as an ocean zoning tool, has been developed to address the sea use conflicts in Chinese coastal and sea waters (Fang et al., 2011; Feng et al., 2016). The MFZ experience in China is in line with MSP practice in the world. After nearly thirty years, a sound marine functional zoning system has been established as a basic sea area utilization management regime in Chinese coastal and sea waters (Fang et al., 2011; Lu et al., 2015; Feng et al., 2016). The implementation of the MFZ system effectively addresses the sea use conflicts, optimizes the ocean-related industry layout, and promotes the rapid growth of marine economy as well as marine environmental conservation (Wang et al., 2014; Feng et al., 2016).

Xiamen is a pilot city to implement MFZ system and a demonstration site of integrated coastal management (ICM) as well in China (Fang et al., 2011; PEMSEA, 2006). Xiamen ICM mode (PEMSEA, 2006) has been summarized that one of its successful elements is at-

Corresponding author.

Email addresses: qhfang@xmu.edu.cn (Q. Fang); dqma@xmu.edu.cn (D. Ma); lyzhang2001@163.com (L. Zhang); 1790622959@qq.com (S. Zhu) 
tached to planning and zoning. However, there is little literature to analyze in-depth how MFZ plays its roles in implementing ICM. Therefore, this paper explores how MFZ has been initiated and continuously developed in the context of ICM practice through the case study in Xiamen. The experiences and lessons of MFZ in Xiamen are analyzed in detail, and further its contribution to ICM as a working approach to shift ICM from a general concept to an on-the-ground practice. This case study will inform policy makers on ICM implementation from a new insight of MFZ or MSP.

In this paper, Section 2 details the development process of MFZ in Xiamen, including the drivers forcing the implementation of MFZ, the procedure of compiling the MFZ scheme, the implementation of MFZ as well as its achievements; Section 3 explores the relationship between ICM and MFZ in Xiamen; lessons learned from MFZ in Xiamen were analyzed in Section 4; Conclusions were finally drawn in Section 5.

\section{The development of marine functional zoning in Xiamen}

\subsection{Drivers to initiate marine functional zoning in Xiamen}

\subsubsection{Competing demands on sea areas in Xiamen Seas}

The Ninth Five-Year Plan (1996 2000) of Xiamen proposed to develop Xiamen to a modern international port and scenic city (Xiamen City Government, 1996a). In terms of developing marine economy, the Xiamen City Government proposed to develop a high level and high beneficial marine industrial system comprising an export-oriented exporting port and shipping, a prosperous coastal tourism industry as well as the intensive marine aquatic industry through implementing the sustainable development strategy. In addition, the Xiamen City Government also attempted to develop Xiamen towards a demonstration plot of coastal integrated management and marine environmental protection (Scientific and Technological Committee of Xiamen, 1998).

The ambitious developing goals therefore posed high demands in limited ocean spaces. For example, reclamation areas increased from $718.21 \mathrm{hm}^{2}$ in 1980 s to $1748.00 \mathrm{hm}^{2}$ in the period of 20012007 (Qiu, 2009; Zhang et al., 2009); the total maricultural area increased from about $3604.33 \mathrm{hm}^{2}$ in $198410087.87 \mathrm{hm}^{2}$ in 1995; the port's handling capacity increased from 3.00 million tons in 1984 to 13.10 million tons in 1995 , and expected to grow to 210.22 million tons by 2015; the tourism industry also developed, with an increase of annual number of international tourists from about 60 thousand in 1984 to 250 thousand by 1995 (Table 1). The rapid development of marine industries and the lack of coordination led to the increase of demands on sea areas, resulting in sea use conflicts. For example, the vast majority of spaces in West Sea and Tongan Bay were occupied by overly dense maricultural activities, consequently, the development of the port and shipping was restricted severely (Peng et al., 2006). In addition, the large scale and extensive mariculural activities also affected the oceanic space demand for developing coastal tourism and other new and emerging ocean-related industries, therefore impeded the development of overall marine industries, and led to failure of meeting the demand of the social and economic development (Peng et al., 2006).

Table 1

Development of marine activities in Xiamen Sea Areas.

Source: * from Li et al. (1998), others from Xiamen Statistics Bureau.

\begin{tabular}{llll}
\hline Year & $\begin{array}{l}\text { Mariculture } \\
\text { areas }\left(\mathrm{hm}^{2)}\right.\end{array}$ & $\begin{array}{l}\text { Port's handling } \\
\text { capacity (million } \\
\text { tons) }\end{array}$ & $\begin{array}{l}\text { Annual international } \\
\text { tourists (number) }\end{array}$ \\
\hline 1984 & 3604.33 & 3.00 & 59936 \\
1995 & 10087.87 & 13.10 & 254409 \\
2007 & 2042.96 & 81.10 & 835531 \\
2015 & 1861.00 & 210.22 & 3170000 \\
\hline
\end{tabular}

\subsubsection{The lack of coordination mechanism among sea uses}

The management of exploiting and utilizing Xiamen sea areas was a typical sector-based management before implementing the Integrated Coastal Management Program in 1994. There existed 15 ocean-related departments or agencies, including Aquatic Bureau, Port Authority, Tourism Bureau, etc. Each sector was responsible for developing their own sectoral plans, exploiting and managing corresponding sectoral activities, while there was no coordination and cooperation among ocean-related sectors (Chua et al., 1997; PEMSEA, 2009). The sector-based management system was unable to tackle sea use conflicts effectively. The lack of a unified plan and integrated management in terms of exploiting and utilizing marine resources led to issues of competing exploitation, repeated exploitation, and damaging and wasting marine resources. In addition to gaps in the management mechanism, there also existed gaps in the sea legislations. The ocean legislation system was composed of specific laws and regulations, lacking an integrated law related to the administration of the use of sea areas (Chua et al., 1997). The disordered marine exploitation activities associating with the sector-based management system restricted the development of marine economy in Xiamen (Chen and Uitto, 2003).

\subsubsection{Severe marine environmental deterioration}

The large scale reclamation activities led to great losses of sea areas and mangroves in Xiamen (Ma et al., 2016). The sea area of Xiamen dropped from $530 \mathrm{~km}^{2}$ in 1950 s to $334 \mathrm{~km}^{2}$ in 1996 , especially the West Sea where the sea area decreased from $110 \mathrm{~km}^{2}$ in 1952 to $72 \mathrm{~km}^{2}$ in 1997 (PEMSEA, 2009), and the area of mangroves decreased from $320.0 \mathrm{hm}^{2}$ in 1960 s to $32.6 \mathrm{hm}^{2}$ in 2000 (Lin et al., 2005). The narrowing sea areas reduced the tidal prism and the current velocity, weakening the marine environmental carrying capacity (Lin et al., 2007; Wang et al., 2013). In addition, the mutual effects of fast growing population and the rapid development of industry on the land as well as the boost of marine activities such as maricultural activities, shipping etc., posed great pressures on marine environment of Xiamen sea areas (Xue et al., 2004; Lin et al., 2007). The sea water in the Xiamen sea area showed a deteriorating trend, e.g. the concentration of organic pollutants in the sediment of the Western Sea increased from $1.5 \%$ in 1980 s to $3.48 \%$ in 2003 (Lin et al., 2007). Moreover, degradation of the marine environment and the increase of marine activities threatened the survival of rare marine species such as Sousa Chinensis, whose observed frequency sharply decreased from 3084 times per year in 1960s to 229 to 531 times per year during 19941998 (Huang, 2012).

\subsection{The procedure of developing a marine functional zoning scheme in Xiamen}

\section{(1) The first Xiamen MFZ scheme (1998 2006)}

In order to guide the intensified marine activities and to achieve rational marine resources use, the first MFZ scheme of Xiamen was initiated by the Xiamen City Government in 1996. A working group was established to develop the MFZ scheme. The draft was completed within two months based on development plans such as The Master Plan of Xiamen City (1995) and The Marine Development Plan of Xiamen City (1993), etc. Then it was submitted to relevant government departments and experts for consultation. After the consultation and review, the revised version was submitted to the Xiamen City Government for approval. The first MFZ scheme was approved by the Xiamen City Government in 1997, and the planning period was from 1998 to 2006. The sea use types in Xiamen were classified into ten categories (with thirty-three subcategories) according to the types of sea uses and characteristics of the natural resources (Xiamen City Government, 
1997a; PEMSEA, 2006; Fang et al., 2011).

(2) Revisions of Xiamen MFZ Scheme (2007 2012) and (2013 2020)

After the approval of Xiamen MFZ Scheme (1998 2006), economic development was triggered after its new Master Plan approved by the State Council of China in 2000, which aiming at expanding development from Xiamen Island $\left(31 \mathrm{~km}^{2}\right)$ to the whole city $\left(1565.09 \mathrm{~km}^{2}\right)$ (State Council of China, 2000). Furthermore, a nationwide guideline, Technical Directives for Marine Functional Zoning, was issued in 1997. These two factors called for a revision of the MFZ scheme. Starting in 2002, the second round MFZ with a planning period of 20072012 was approved by the Fujian Provincial Government in 2007. The latest MFZ scheme with a planning period of 20132020 which began to revise in 2011 was approved by the Fujian Provincial Government in 2016 (Fig. 1).

\section{(3) Evolution of the Xiamen MFZ schemes}

To date, the Xiamen MFZs has experienced three rounds (Table 2). The process for developing a MFZ scheme including technical methods become more sophisticated. The Technical Directives for Marine Functional Zoning has been followed since the second round MFZ (Fang et al., 2011).

The authority to approve the MFZ was transformed from the Xiamen City Government to the Provincial Government according to the Law of the People's Republic of China on the Sea Areas Use Management (2001).

Regarding the consultation, the working group has paid more attention to stakeholder participation at the preparatory stage since the second round MFZ. The responsible authority organized 12 consulting meetings regarding the draft of MFZ scheme at the second round MFZ (Xiamen City Government, 2006), and a total number of 32 departments including the provincial government departments and the military sector were consulted at the third round MFZ (Xiamen City Government, 2016a).

In addition, the latest MFZ scheme was developed on the basis of the provincial MFZ scheme. The work for developing the latest MFZ scheme has been emphasized on the coherence to other provincial and municipal plans such as the national and provincial MFZ schemes, the Marine Environmental Protection Plan of Fujian Province (2011 2020), and the Master Plan of the Xiamen City (2010 2020), etc.

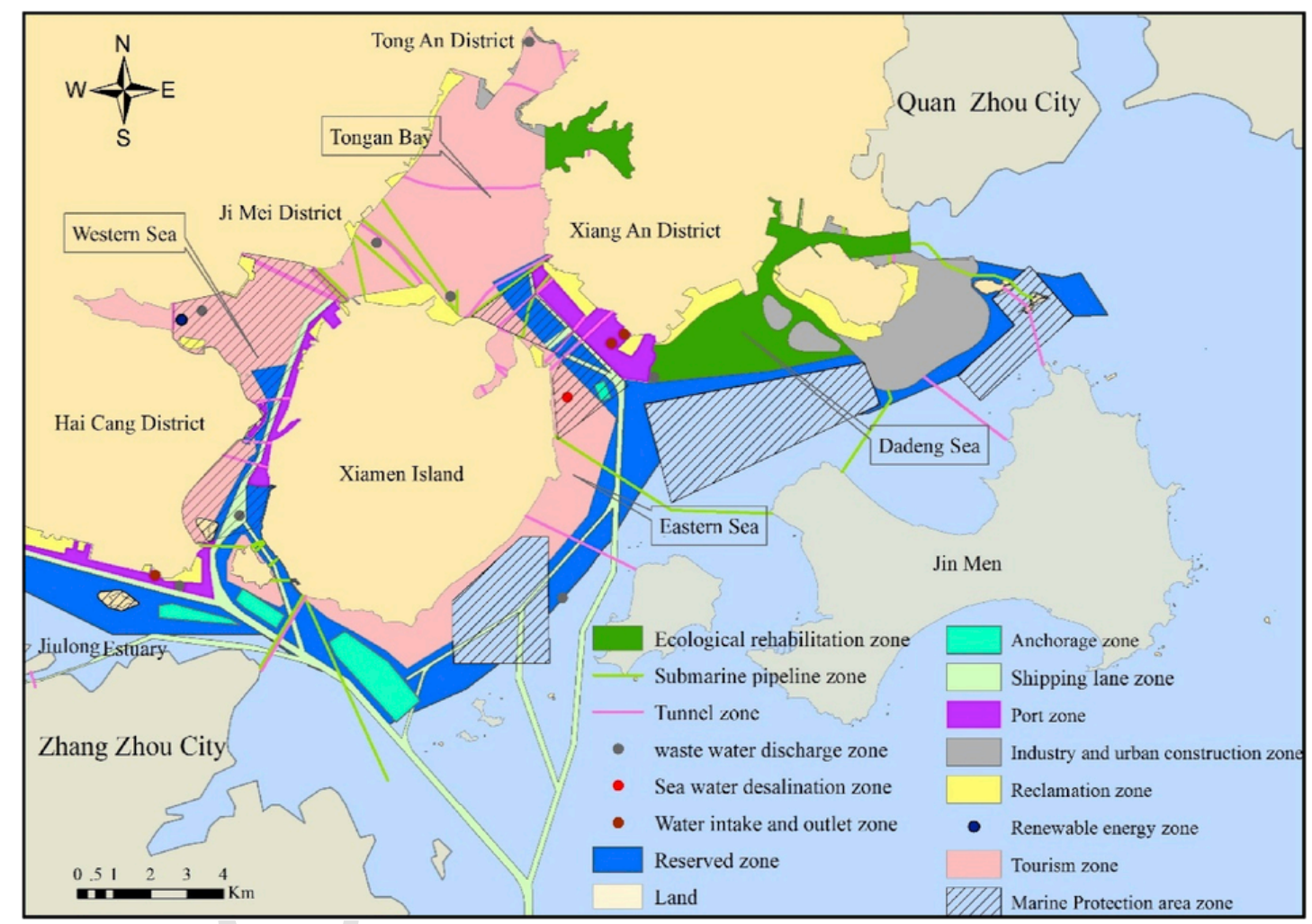

Fig. 1. Marine function zoning scheme of Xiamen (2013 2020).

Table 2

Evolution of the Xiamen MFZ scheme.

\begin{tabular}{|c|c|c|c|c|c|}
\hline $\begin{array}{l}\text { MFZ } \\
\text { scheme }\end{array}$ & $\begin{array}{l}\text { Approval } \\
\text { year }\end{array}$ & $\begin{array}{l}\text { Planning } \\
\text { period }\end{array}$ & Approval authority & Stakeholder participation & $\begin{array}{l}\text { Consideration of the provincial } \\
\text { MFZ scheme }\end{array}$ \\
\hline $\begin{array}{l}\text { First } \\
\text { round }\end{array}$ & 1997 & 19982006 & $\begin{array}{l}\text { Xiamen City } \\
\text { Government }\end{array}$ & No consultation & No provincial scheme \\
\hline $\begin{array}{l}\text { Second } \\
\text { round }\end{array}$ & 2007 & 20072012 & $\begin{array}{l}\text { Fujian Provincial } \\
\text { Government }\end{array}$ & Organizing 12 consulting meeting & Considering compatibility \\
\hline $\begin{array}{l}\text { Third } \\
\text { round }\end{array}$ & 2016 & 20132020 & $\begin{array}{l}\text { Fujian Provincial } \\
\text { Government }\end{array}$ & $\begin{array}{l}\text { Further strengthened, all governmental } \\
\text { departments were consulted }\end{array}$ & $\begin{array}{l}\text { Developing after the provincial } \\
\text { MFZ scheme }\end{array}$ \\
\hline
\end{tabular}




\subsection{Implementing Xiamen $M F Z$}

Implementation of a planning is as important as its development. Regardless how good is a MFZ scheme, it can not be put into force without effective enforcement. In Xiamen MFZ case, the various legislation from national laws to local regulations has ensured the legal status of MFZ, which lays the foundation for MFZ enforcement; clear responsible department and integrated marine force for implementing MFZ is established in Xiamen; and an expert group also contributes.

\section{(1) legislation}

In terms of legislation, the Xiamen City Government enacted the Regulation for the Management of Sea Area Use in Xiamen in 1997, calling for the Xiamen City Government in accordance with the principles of laws and provisions to develop marine functional zoning and marine economic development planning for conducting integrated management of the use of sea areas, and prohibiting sea uses which were in contradiction with the MFZ scheme and the marine economic development planning of Xiamen (Xiamen City Government, 1997b). Since then, the Central Government made efforts on legislation to develop the MFZ system as a basic legal regime for the administration of sea areas in China. In detail, the Marine Environment Protection Law of the People's Republic of China (Revision in 1999) and the enactment of Law of the People's Republic of China on the Sea Areas Use Management in 2001 established the legal status of MFZ (Fang et al., 2011; Feng et al., 2016). The Article 6 of the Marine Environment Protection Law of the People's Republic of China requires that the State oceanic administrative department shall, in conjunction with the relevant departments of the State Council and the people's governments of the coastal provinces, autonomous regions and municipalities directly under the Central Government, work out a national marine functional zonation scheme and submit it to the State Council for approval. The coastal local people's governments shall, in accordance with the national and local marine functional zonation schemes, make use of the sea areas in a scientific and rational way , and its Article 7 requires that the State shall draw up, in accordance with the marine functional zoning scheme, national marine environment protection plan and regional marine environment protection plans in key sea areas (Standing Committee of the National People's Congress, 1999). Besides, according to the Article 4 of Law of the People's Republic of China on the Sea Areas Use Management, the State practices the system of functional division of the sea. The use of sea areas shall be in conformity with the functional divisions of the sea (Standing Committee of the National People's Congress, 2001).

\section{(2) enforcement and monitoring}

With respect to enforcement and monitoring, the Xiamen Oceans and Fisheries Bureau as the competent authority of the ocean administration is responsible for guiding, coordinating and monitoring the implementation of the MFZ scheme; an integrated marine enforcement squad was established to investigate and treat behaviors against the MFZ scheme in 1997 (PEMSEA, 2009).

\section{(3) expert group}

The Marine Experts Group whose members coming from five ocean-related institutions located in Xiamen including Xiamen University, the Third Institute of Oceanography of State Oceanic Administration was established to provide strong scientific and technical supports for developing MFZ.

\subsection{The achievements of MFZ in Xiamen}

2.4.1. A management system of ordered marine exploitation and utilization Xiamen MFZ was developed based on the goals of the economic and social development plan, linking up other ocean-related industrial plans. Therefore, the MFZ scheme guaranteed the sea use demands for the economic and social development of Xiamen. The Xiamen City Government strictly implemented the MFZ scheme, only those the sea-use project in conformity with the MFZ scheme can be approved. Since the implementation of second MFZ in 2007, the consistency rate of all sea-use projects approval with the MFZ scheme reached $99.63 \%$. The implementation of MFZ avoided the issue of disordered, excess and unpaid use of sea areas, and established a good order to exploit and manage the sea areas in Xiamen (Xiamen City Government, 2016a).

\subsubsection{Sea use allocation for blue economy development}

Xiamen is a coastal city with rich harbor and tourism resources. The advantageous natural conditions provide huge potential for developing the port and shipping industry (Cai and Chen, 2012). Therefore, both industries of port \& shipping and tourism have been determined as the development priority in its Master Plan in Xiamen (State Council of China, 2000). The harbor and tourism resources were fully utilized through scientifically allocating marine recourses in the MFZ Scheme to different uses to avoid conflicts. For example, maricultural activities in non-culture zones were phased out, maricultural areas decreased from $10087.87 \mathrm{hm}^{2}$ in 1995 to $1681 \mathrm{hm}^{2}$ in 2015 (Xiamen City Government, 1996b, 2016b). By contrast, the port and shipping area accounted for $4939 \mathrm{hm}^{2}$ by 2013 (Xiamen City Government, 2016a).

In addition, the MFZ optimized the layout the marine industries, promoting the fast growth of the new and emerging marine industries such as the yacht industry. The designation of marine protected areas also mitigates the conflict between utilizing and protecting rare marine species.

The overall benefits of utilizing marine resources in the Xiamen sea area improved remarkably, with a proportion of the gross output value of marine industries accounting for the GDP increasing from about 5\% in 1998 to $14.4 \%$ in 2015 (Xiamen City Government, 1999, 2016b).

\subsubsection{The conservation of rare marine species}

There are three kind of rare species including Sousa Chinensis, Branchiostoma sp. and Egrets in Xiamen seas. A national marine protected area (MPA) was established in the Xiamen Sea area in 2000 (Dong et al., 2011). The location and area of the MPA is one of main considerations in the process of developing a MFZ scheme. The boundary of the MPA was delimitated through MFZ (Fig. 1).

The MFZ requires that all activities against the conservation goals shall be prohibited, and the water quality within the MPA shall comply with the first class of National Seawater Quality Standards of China. According to the latest MFZ scheme, the area of the MPA reached $7588 \mathrm{hm}^{2}$. The implementation of MFZ strengthens the management of the MPA.

As a consequence, the number of Sousa Chinensis remains stable in the context of rapid development of social economy according to the field observation with an observed frequency ranging from 284 to 542 times per year in the period of 20102013 (Xiamen Oceans and Fisheries Bureau, 2011, 2012; 2013, 2014).

In addition, the MFZ scheme specified the sea water quality requirements for each functional zone, which provided a scientific basis for monitoring and evaluating sea water quality of Xiamen Sea Area. The establishment of sea water quality monitoring mechanism also contributes to the conservation of rare marine species. 


\section{Importance of MFZ for ICM in Xiamen}

\subsection{Xiamen ICM mode}

The ICM is an integrated governance framework to manage activities in coastal zones aiming at achieving the sustainable development of coastal areas (Cicin-Sain et al., 1998). It is a continuous, iterative, adaptive and consensus-building process comprised of a set of goals for the sustainable development of coastal areas (Bower et al., 1994). In 1994, Xiamen was selected as a demonstration site to apply ICM to manage coastal development. The efforts on legislation and planning, coordinating mechanism, integrated law enforcement, scientific and technologic support and public participation guaranteed the success of implementing ICM program in Xiamen, which was regarded as Xiamen ICM mode (PEMSEA, 2006).

In terms of legislation, a sound coastal management legal system comprised of a set of laws and regulations such as the Regulation on the Uses of Xiamen Sea Areas has been developed to provide the legal basis for implementing ICM program, and an integrated law enforcement squad involving marine related agencies has been established to surveil and manage ocean-related activities so as to ensure the effective law enforcement.

Besides, the Xiamen City Government established a Marine Management Coordination Committee (MMCC) in charge of coordinating and addressing conflicts of development demands and resources utilization among sectors. The head of the MMCC is the Xiamen's Executive Vice-Mayor and its members come from 22 government agencies. This Coordination Committee provided a good coordination mechanism to coordinate and manage ICM activities so as to achieve inter-sectoral integration of coastal management.

In addition, a Marine Experts Group composed of scientists and experts from different disciplinary backgrounds was established to provide scientific support and advice to policymakers when developing potential projects, achieving the integration of science and management as well as integration among disciplines (PEMSEA, 2006; Mao and Kong, 2018 this issue).

Regarding public participation, the Xiamen City Government also encouraged the public to participate in marine environmental protection through reflecting issues to local government by sending letters, petition or phone calls (Hu and Shi, 1998).

\subsection{The roles of MFZ in Xiamen ICM mode}

In the case of Xiamen, MFZ is an essential part of the ICM program (Chua et al., 1997; Peng et al., 2006). The MFZ is an operational approach to implement the ICM program in the aspect of managing the uses of sea areas. The concept of ICM was structured into the ocean management practice through the implementation of MFZ (Table 3).

The legal regime of sea use management that requires implementing MFZ system is one part of the legal framework of Xiamen ICM. One task of the MMCC for coordinating ICM is to prepare and coordinate the MFZ scheme. The implementation of MFZ achieved the coordinated and inter-sectoral management in terms of sea uses, addressing issues of sea use conflicts and the disordered ocean management in Xiamen (Peng et al., 2006). In addition, the Marine Experts Group also plays an important role in compiling a MFZ scheme through reviewing the draft of the MFZ scheme. For the implementation stage of MFZ, one of duties of the integrated marine enforcement squad is to ensure the effective enforcement and compliance of the MFZ scheme.
Table 3

Relationship between ICM and MFZ in Xiamen.

\begin{tabular}{ll}
\hline $\begin{array}{l}\text { Xiamen ICM } \\
\text { mode }\end{array}$ & MFZ \\
\hline Legislation & $\begin{array}{l}\text { The MFZ legal regime is an essential part of the Xiamen ICM } \\
\text { legal framework } \\
\text { Preparing and coordinating the development of the MFZ } \\
\text { scheme is one of the main tasks of the Marine Management } \\
\text { Coordination Committee (MMCC) established under Xiamen } \\
\text { ICM mode } \\
\text { mechanism }\end{array}$ \\
$\begin{array}{l}\text { Scientific } \\
\text { and } \\
\text { technologic } \\
\text { support }\end{array}$ & $\begin{array}{l}\text { Reviewing the draft of the MFZ scheme is one of the main tasks } \\
\text { Integrated } \\
\text { law } \\
\text { enforcement }\end{array}$ \\
$\begin{array}{l}\text { Public } \\
\text { participation }\end{array}$ & $\begin{array}{l}\text { The MFZ scheme provides the legal basis for the surveillance } \\
\text { and management of marine activities under Xiamen ICM mode } \\
\text { conducted by the integrated law enforcement squad } \\
\text { Participating in developing the MFZ scheme is the main } \\
\text { activity of stakeholders participation in the integrated coastal } \\
\text { management }\end{array}$ \\
\hline
\end{tabular}

\subsection{MFZ's contribution to integration in Xiamen ICM}

Many Xiamen ICM experiences show its success of various integration including intergovernmental integration, intersectoral integration, integration of land and sea, integration of science and management and integration among disciplines (PEMSEA, 2006). As an up-scaling efforts of Xiamen ICM, Jiulong River-Xiamen Bay Ecosystem-Management Strategic Action Plan was developed in 2011 to establish a trans-boundary cooperation mechanism among three cities of Xiamen, Zhangzhou and Longyan for addressing marine pollution issues from Jiulong River among three cities of Xiamen, Zhangzhou and Longyan (State Oceanic Administration et al., 2012).

The MFZ system, as an operational approach to implement the concept of ICM, has also mainstreamed integration into its developing, approval and implementation stages (Table 4).

1) The Xiamen MFZ scheme is developed after according to the provincial MFZ, which means the sea-use functional zones in junctional zones among adjacent cities are compatible. The intergovernmental integration of MFZ is achieved through the trans-boundary cooperation of MFZ coordinated by the provincial government.

2) The MFZ scheme also contributes to the intersectoral integration because the MFZ scheme is a result of coordination of all sectoral demands on sea areas.

3) All sectoral plans including reclamation shall conform to the MFZ scheme in terms of sea uses, and the land use plan shall conform to the MFZ scheme which achieves the integration of land and sea.

4) The MFZ scheme is the outcome of completed understandings and systematic studies of natural features of the marine environment,

Table 4

MFZ for integration in ICM.

\begin{tabular}{|c|c|}
\hline Integration in ICM & MFZ \\
\hline $\begin{array}{l}\text { Intergovernmental } \\
\text { Integration }\end{array}$ & $\begin{array}{l}\text { Achieving trans-boundary cooperation among adjacent } \\
\text { cities }\end{array}$ \\
\hline Intersectoral & The MFZ scheme is an overall sea use plan based on \\
\hline Integration & coordinating sectoral sea use demands \\
\hline Land and sea & The land use plan shall conform to the MFZ scheme \\
\hline \multicolumn{2}{|l|}{ Integration } \\
\hline $\begin{array}{l}\text { Science and } \\
\text { management }\end{array}$ & $\begin{array}{l}\text { The MFZ scheme is developed based on best } \\
\text { understanding of the natural ecosystem and }\end{array}$ \\
\hline Integration & socioeconomic conditions \\
\hline $\begin{array}{l}\text { Multiple } \\
\text { disciplinary }\end{array}$ & $\begin{array}{l}\text { The working group for developing a MFZ scheme comes } \\
\text { from different disciplinary backgrounds }\end{array}$ \\
\hline Integration & \\
\hline
\end{tabular}


features of marine resources and demands of sea uses, which is conducted by experts from different disciplinary backgrounds.

5) The process of developing MFZ is actually a process of integrating science into decision-making and management.

\section{Discussion}

The Xiamen MFZ has effectively addressed the various sea use conflicts, protected rare marine species by allocating sea areas for its conservation, and marine environmental quality has also been maintained in the rapid economic development. And MFZ has been structured in Xiamen ICM mode which is very important for Xiamen coastal sustainable development. Despite the above achievements of Xiamen MFZ, there are some spaces to improve in stakeholders participation, performance evaluation and land-sea integration.

\section{(1) Stakeholders participation}

Currently in the MFZ developing process, stakeholders participation has become an important step which should not be neglected. Although stakeholders including governmental departments are consulted, non-governmental organizations (NGOs) have not been widely consulted. The reasons include the insufficiency of relevant NGOs in number and activities. Fishermen also have not yet fully participated in the whole process of developing a MFZ scheme although their interest has been traditionally considered by the Fishery Department. For general public, the awareness of participation is still low. This has prevented the MFZ scheme from full consideration of all interests of all stakeholders.

\section{(2) Performance evaluation}

The necessity of evaluation has been highlighted in international practice in recent years for an adaptive MSP (Douvere and Ehler, 2011; Carneiro, 2013). It is the same for MFZ in China. According to the National Marine Functional Zoning Scheme (2011 2020), it is required to establish the MFZ implementation monitoring system (State Council of China, 2012). However, the evaluation still lacks a systematic methodology and a process of opening to the public, which shall be improved in the future.

\section{(3) Land-sea integration}

The MFZ scheme covers sea areas is binding on ocean-related activities only, while the adjacent land and the upstream watershed as well as the relevant land development activities are not involved. As a consequence, the issue of land-based source pollution especially pollutants from rivers cannot be addressed by the MFZ. Therefore, a new coordination mechanism that integrating various types of spatial plans into a single master plan shall be developed.

\section{Conclusions}

Marine Functional Zoning (MFZ) was initiated by local drivers in Xiamen and has been sequentially upgraded in the past two decades, which has also witnessed the great development of marine spatial planning (MSP) around the world. The key drivers include conflicts among different sea uses which posed increasing demands on sea areas particularly resulted by a rapid economic growth in this period, and the conflicts between sea uses and marine environments. Both conflicts were exacerbated due to the lack of coordination mechanism when integrated coastal management (ICM) was not in place.

Based on the well-functioned guidelines and the legal regulations, MFZ practice in Xiamen has demonstrated its technical and managerial feasibility to address the above conflicts. More importantly, with sci- ence-informed process and future-oriented perspective, the sea areas for blue economy have been guaranteed in the MFZ schemes in Xiamen.

Beyond that, it has contributed to the adoption and development of the concept of ICM in Xiamen. ICM with integration as a core, needs a working platform to put it into ground. MFZ has provided the integration approach in Xiamen, including intergovernmental integration, inter-sectoral integration, land-sea integration, science-management integration, and multiple-disciplinary integration.

Challenges still remain, an ecosystem-based management approach will be prominent to promote land-sea integration and effectively address trade-offs between economic development and marine conservation; stakeholders participation and performance monitoring \& evaluation will be critical for a sustainable MFZ in line with the Sustainable Development Goals in coastal area. Xiamen MFZ experience provides a positive case study, however, considering the different and changing natural and socio-economic environments, practices elsewhere shall be customized to its own contexts.

\section{Acknowledgements}

This work was financially supported by the National Natural Science Foundation of China (41376114) and the National Key Research and Development of Program of China (2017YFC0506105).

\section{References}

Agardy, T., Sciara, Di, N, G., Christie, P., 2011. Mind the gap: addressing the shortcomings of marine protected areas through large scale marine spatial planning. Mar. Policy 35 (2), 226-232.

Bower, B.T., Ehler, C.N., Basta, D.J., 1994. Office of Ocean Resources Conservation and Assessment: a Framework for Planning for Integrated Coastal Zone Management. National Ocean Service, National Oceanic and Atmospheric Administration, Silver Spring, MD.

Cai, J.S., Chen, W.Q., 2012. Economic analysis for coastal principal function selection: case study of Xiamen Bay. Adv. Mater. Res. 347, 1214-1219.

Carneiro, G., 2013. Evaluation of marine spatial planning. Mar. Policy 37, 214-229.

Chen, S., Uitto, J.I., 2003. Governing marine and coastal environment in China: building local government capacity through international cooperation. China Environ. Ser. 6, 67-80.

Chua, T., Yu, H.M.C., G.Q, 1997. From sectoral to integrated coastal management: a case in Xiamen, China. Ocean Coast. Manag. 37 (2), 233-251.

Cicin-Sain, B., Knecht, R.W., Jang, D., Fisk, G.W., 1998. Integrated Coastal and Ocean Management: Concepts and Practices. Island Press, Washington DC.

Collie, J.S., Beck, M.W., Craig, B., Essington, T.E., Fluharty, D., Rice, J., Sanchirico, J.N., 2013. Marine spatial planning in practice. Estuarine. Coast. Shelf Sci. 117, 1-11.

Day, J.C., 2002. Zoning lessons from the great barrier reef marine park. Ocean Coast. Manag. 45 (2), 139-156.

Dong, L., Hong, X.Y., Zou, J.Y., 2011. Study on the space conflict of management of the national marine protected area in Xiamen and the legal solution thereof. In: Remote Sensing, Environment and Transportation Engineering (RSETE), 2011 International Conference on. IEEE, pp. 3595-3598.

Douvere, F., 2008. The importance of marine spatial planning in advancing ecosystem-based sea use management. Mar. Pol. 32 (5), 762-771.

Douvere, F., Ehler, C.N., 2009. New perspectives on sea use management: initial findings from European experience with marine spatial planning. J. Environ. Manag. 90 (1), 77-88.

Douvere, F., Ehler, C.N., 2011. The importance of monitoring and evaluation in adaptive maritime spatial planning. J. Coast. Conserv. 15 (2), 305-311.

Ehler, C., Douvere, F., 2006. Visions for a Sea Change, Report of the First International Workshop on marine Spatial Planning. Intergovernmental Oceanographic Commission and Man and the Biosphere Programme. IOC manual and guides, Paris.

Fang, Q.H., Zhang, R., Zhang, L.P., Hong, H.S., 2011. Marine functional zoning in China: experience and prospects. Coast. Manag. 39 (6), 656-667.

Feng, R.Y., Chen, X.X., Li, P., Zhou, L.L., Yu, J., 2016. Development of China's marine functional zoning: a preliminary analysis. Ocean Coast. Manag. 131, 39-44.

Gilliland, P.M., Laffoley, D., 2008. Key elements and steps in the process of developing ecosystem-based marine spatial planning. Mar. Pol. 32 (5), 787-796.

Hu, M.H., Shi, Q., 1998. A public awareness programme on the coastal environment for the Xiamen demonstration site. In: Xiamen Demonstration Project Regional Programme for the Prevention and Management of Marine Pollution in the East Asian Seas, (In Chinese).

Huang, C.X., 2012. Ecosystem Health Assessment in Coastal Regional Decision Making. Master Thesis of Xiamen University, (in Chinese).

Kenchington, R.A., Day, J.C., 2011. Zoning, a fundamental cornerstone of effective marine spatial planning: lessons learnt from the great barrier reef, Australia. J. Coast. Conserv. 15 (2), 271-278.

Li, S.J., Du, Q., Lu, Z.B., et al., 1998. Abatement and management of pollution from coastal aquaculture. In: Xiamen in Xiamen Demonstration Project: Regional Pro- 
gramme for the Prevention and Management of marine Pollution in the East Asian Seas, (in Chinese).

Lin, P., Zhang, Y.H., Yang, Z.W., 2005. Protection and ecological restoration of man-groves in Xiamen. J. Xiamen Univ. 44, 1-6, (in Chinese).

Lin, T., Xue, X.Z., Lu, C.Y., 2007. Analysis of coastal wetland changes using the DPSIR model: a case study in Xiamen, China. Coast. Manag. 35 (2 3), 289-303.

Lu, W.H., Liu, J., Xiang, X.Q., Song, W.L., McIlgorm, A., 2015. A comparison of marine spatial planning approaches in China: marine functional zoning and the marine ecological red line. Mar. Policy 62, 94-101.

Ma, D.Q., Fang, Q.H., Liao, S.H., 2016. Applying the Ocean Health Index framework to the city level: a case study of Xiamen, China. Ecol. Indic. 66, 281-290.

Mao, Z., Kong, H., 2018. The evolution of operational modality of ICM in Xiamen. Ocean Coast. Manag.(Submitted) in this Special Issue.

Olsen, E., Fluharty, D., Hoel, A.H., Hostens, K., Maes, F., Pecceu, E., 2014. Integration at the round table: marine spatial planning in multi-stakeholder settings. PLoS One 9 (10), 1-9.

PEMSEA, 2006. Xiamen: an ICM Journey. PEMSEA Technical Report No. 18 second ed. Global Environment Facility/United Nations Development Programme/United Nations Office for Project Services (GEF/UNDP/UNOPS) Partnerships in Environmental Management for the Seas of East Asia (PEMSEA), Quezon City, Philippines.

PEMSEA, 2009. Xiamen's Transition to Orderly Seas. Case Study, vol. 1, Global Environment Facility/United Nations Development Programme/United Nations Office for Project Services (GEF/UNDP/UNOPS) Partnerships in Environmental Management for the Seas of East Asia (PEMSEA), Quezon City, Philippines, No. 2, 2009.

Peng, B.R., Hong, H.S., Xue, X.Z., Jin, D., 2006. On the measurement of socioeconomic benefits of integrated coastal management (ICM): application to Xiamen, China. Ocean Coast. Manag. 49 (3), 93-109.

Qiu, H.Y., 2009. Study on the Process of Sea Reclamation in Xiamen City. Master Thesis of Xiamen University, (in Chinese).

Santos, C.F., Agardy, T., Andrade, F., Barange, M., Crowder, L.B., Ehler, C.N., Orbach, M.K., Rosa, R., 2016. Ocean planning in a changing climate. Nat. Geosci. 9 (10), 730730 .

Scientific and Technological Committee of Xiamen, 1998. Implementing the Blue Plan to revitalize marine science and technology: the third section of Eight Plans regarding science and technology progress in the Ninth Five-Year Plan of Xiamen. Xiamen Sci. Technol. 2, 1-2, (In Chinese).

Standing Committee of the National People s Congress, 1999. Marine Environment Protection Law of the People's Republic of China (Revision in 1999).

Standing Committee of the National People s Congress, 2001. Law of the People's Republic of China on the Sea Areas Use Management.

State Council of China, 2000. The Master City Plan of Xiamen, (In Chinese).
State Council of China, 2012. National Marine Functional Zoning Scheme (2011-2020).

State Oceanic Administration, 2012. Xiamen Oceans and Fisheries Bureau. Jiulong River-Xiamen Bay Ecosystem-Management Strategic Action Plan. Partnerships in Environmental Management for the Seas of East Asia (PEMSEA), Quezon City, Philippines, PEMSEA.

Vince, J., 2014. Oceans governance and marine spatial planning in Australia. Aust. J. Marit. Ocean Aff. 6 (1), 5-17.

Wang, J., Hong, H.S., Zhou, L.M., Hu, J.Y., Jiang, Y.W., 2013. Numerical modeling of hydrodynamic changes due to coastal reclamation projects in Xiamen Bay, China. Chin. J. Oceanol. Limnol. 31 (2), 334-344.

Wang, H.H., Li, M.R., Hu, N.P., Gao, Y.M., 2014. Utilization effectiveness of marine functional zones using system dynamics for China: modeling and assessment. J. Coast. Conserv. 18 (6), 609-616.

Xiamen City Government, 1996a. The Ninth Five-year Plan of Xiamen, (In Chinese).

Xiamen City Government, 1996b. Yearbook of Xiamen Special Economic Zone of 1995, (In Chinese).

Xiamen City Government, 1997a. Marine Functional Zoning Scheme of Xiamen in 1997, (In Chinese).

Xiamen City Government, 1997b. Regulations for the Management of Sea Area Use in Xiamen, (In Chinese).

Xiamen City Government, 1999. Yearbook of Xiamen Special Economic Zone of 1998, (In Chinese).

Xiamen City Government, 2006. Marine Functional Zoning Scheme of Xiamen (2007-2012), (In Chinese).

Xiamen City Government, 2016a. Marine Functional Zoning Scheme (2013 2020) of Xiamen, (In Chinese).

Xiamen City Government, 2016b. Yearbook of Xiamen Special Economic Zone of 2015, (In Chinese).

Xiamen Oceans and Fisheries Bureau, 2011. 2010 Bulletin of Marine Environmental Quality in Xiamen, (In Chinese).

Xiamen Oceans and Fisheries Bureau, 2012. 2011 Bulletin of Marine Environmental Quality in Xiamen, (In Chinese).

Xiamen Oceans and Fisheries Bureau, 2013. 2012 Bulletin of Marine Environmental Quality in Xiamen, (In Chinese).

Xiamen Oceans and Fisheries Bureau, 2014. 2013 Bulletin of Marine Environmental Quality in Xiamen, (In Chinese).

Xue, X.Z., Hong, H.S., Charles, A.T., 2004. Cumulative environmental impacts and integrated coastal management: the case of Xiamen, China. J. Environ. Manag. 71 (3), 271-283.

Zhang, L.P., Jiang, Y.W., Chen, W.Q., et al., 2009. Study on the Mathematical Model and the Environment of Fujian Bay, a Case Study of Xiamen Bay. Ocean Press, Beijing, (In Chinese). 